\title{
Practical Applications of Quality Tools in Polish Manufacturing Companies
}

\author{
Beata Starzyńska \\ Poznan University of Technology, Faculty of Mechanical Engineering and Management, \\ Piotrowo Street 3, 60-965 Poznań, Poland, beata.starzynska@put.poznan.pl
}

\begin{abstract}
Background and Purpose: Modern companies have found themselves in a situation where the ability for the dynamic adaptation to the changing market conditions is a key competitive advantage. Therefore they are continually searching for intensive ways of improvement of their processes and products. The basis for the implementation of such strategy is the efficient use of information resources. In quality management, appropriate tools and techniques equip decisionmakers with information, necessary to take: correction, corrective, preventive, and finally - improvement actions.

Design/Methodology/Approach: The paper presents the results of the survey, conducted on a representative sample of manufacturing companies in Great Poland (region of Poland). The main goal of the survey was to ascertain, from the quality assurance perspective, what kind of problems, at which stage of production process are the most frequent and what kind of quality tools and techniques are used by practitioners for their solutions. Furthermore, the respondents evaluated the importance of appearing problems as well as the effectiveness of used tools.

Results: The results of the survey show that quality tools are most frequently implemented at the manufacturing phase of the production process, then at the production set-up stage and measurement phase. On the manufacturing phase example it was shown, which of the tools included in the survey, are effectively used for problem solutions, concerning the process inputs, process performance and management of the processes.

Conclusion: The obtained results allow contradicting the thesis spreading quality tools universality. In the context of production process stages, some of them are oriented towards selected phases and, such as, may be effectively used by practitioners.
\end{abstract}

Keywords: quality management; quality tools \& techniques; process improvement; manufacturing processes

\section{Introduction}

Modern companies found themselves in a situation where the ability of a dynamic adaptation to changing market conditions is a key competitive advantage. This means that all the employees of companies responsible and involved in the process must be equipped with right tools, enabling them to quickly and easily take effective improvement activities in all the areas of value creation for the customer. In the manufacturing companies, process improvement, understood as the increase of process ability to meet the requirements, is implemented in the form of two strategies: extensive and intensive actions. The basis of the realization of strategy of intensive activities (small-step ongoing improvement activities) is the efficient use of the available resources, with particular emphasis on information resources. In the case of quality management, including the aforementioned function of improvement, in order to collect and process data and information, one uses instruments, traditionally described as quality tools and techniques (QT \& T). They equip decision-makers with properly processed information necessary to take: correction, corrective, preventive, and finally - improvement actions in manufacturing processes.

According to (McQuater et al., 1995), tools and techniques are practical ways, skills, means or mechanisms that are used in the realization of specified tasks. In (McQuater et al., 1996) the concept of techniques and

Received: September $6^{\text {th }}, 2013$; revised: $8^{\text {th }}$ July 2014 ; accepted; July $27^{\text {th }}, 2014$ 
tools of quality management is described as a means of practical conduct, skills and instruments applicable to specific tasks, including facilitation of changes or improvements. In (McQuater et al., 1995) and (Dale and McQuater 1998) a quality tool is defined as a specific procedure, focused on a particular task and used independently. In (Gregory, 1993), tools are also defined as those that integrate, to some extent, external requirements with the results of the organization's internal operations. In (Dean and Bowen, 1994) a technique is described as a specified, step by step, procedure method applied with the intention of making practical action more effective. On the other hand, in (McQuater et al., 1995) a technique is defined as a set of tools. In (Dale and McQuater, 1998) the definition of a technique is clarified as a comprehensive, integrated approach to problem solving, based on the usage of a number of supportive tools. As a result, the SPC is a technique, determined by a set of applicable tools in statistical process control: control charts, histograms, graphs, etc. Examples of techniques are also: QFD, FMEA, DOE. According to (Bamford and Greatbanks, 2005), the tools and techniques of quality management enable:

- examination of the areas that cause the most problems;

- presentation of complex data in a simple and transparent way;

- determination of the causes of problems;

- identification of the causes of process variation;

- showing the distribution of the data;

- showing the relationships between the variables of the process;

- setting priorities for action.

One can also generalize the benefits arising from the application of quality tools and techniques in terms of processes and entities. In the first case it is:

- improvement (McQuater et al., 1995), (Bunney and Dale, 1997), (Herbert, Curry and Angel, 2003), (Bamford and Greatbanks, 2005), (Lagrosen and Lagrosen, 2005), (Tari, Molina and Castejon, 2007)

- increase in productivity (Herbert, Curry and Angel, 2003).

In the second:

- increase of pro-quality awareness (Lagrosen and Lagrosen, 2005);

- increased commitment in relation to quality issues (Lagrosen and Lagrosen, 2005);

- promoting work in teams (Herbert, Curry and Angel, 2003);

- facilitating communication (Herbert, Curryand Angel, 2003), (Ahmed Hassan, 2003);

- increase of customer satisfaction (Lagrosen and Lagrosen, 2005).

From the point of view of practical application of quality tools and techniques, divisions of instruments, locating individual instruments in methodologies of organizational activities, are very important. These include the described in the literature methods:

- problem solving (Ahmed and Hassan, 2003), (Fukui et al., 2003), (Rooney and Heuvel, 2004), (Tague, 2005), (Tang et al., 2007);

- improvement (Brassard and Ritter, 1994), (Asaka and Ozeki, 1996), (Shiba and Walden, 2002), (Bamford and Greatbanks, 2005), (Tague, 2005).

The starting point for the search of useful tools in practice is most frequently methodical sphere of activities carried out in order to solve a problem or improve the implementing process. In this way - tools are associated with the stages of the methodologies of organization activities, such as PDCA (Dahlgaard et al., 2013). The variety of the offered methodologies of problem solving/process improvement causes that the proposed, in their framework, sets of quality tools and their assignment to the various phases of methodologies, differ from one another (for example in (Brassard and Ritter, 1994; Shiba and Walden, 2002; Fukui et al., 2003). In the studies there is no "bottom-up" perspective on the matter yet, which would include while selecting appropriate tools and techniques of quality management - knowledge and experience of practitioners, either directly or indirectly involved in the realization of the improved processes. In the studies one has tried to prove the hypothesis that the choice of quality tools and techniques is dependent on the particular stage in the production process and on the nature of the problems, which they are intended to solve.

\section{Methodology}

In the conducted study, as the subject of statistical population, one has specified a company with already implemented standardized management system that meets at least one of the quality management standards (e.g. ISO 9001, ISO 14001, EMAS, GMP, etc.); however the possession of the certificate system was not a necessary condition. Possession of standardized management system was to guarantee the existence of the so-called pro-quality awareness in the given enterprise.

As the test body a manufacturing and / or service company has been chosen (where the services offered require the implementation of technological process). The study adopted a group of companies in accordance with the code of the European Classification of Economic Activities NACE. In order to ensure that the sample is representative and that sampling is current and complete, an online database of companies has been used. It was made available by the company, which is engaged in the professional development of databases.

The study adopted a limit to the sampling methodology. The main criterion for selection was a deliberate restriction to a geographical segment (Wielkopolska region) with 
simultaneous maintenance of the representativeness of the sample and the selection of the quota. The population of the surveyed companies was divided into layers: (a1) manufacturing companies, (a2) production and service companies, (a3) production and trade enterprises, (a4) manufacturing, service \& trade companies, (a5) commercial enterprises, (a6) service companies, (b1) small enterprises (employing up to 50 people), (b2) medium-sized enterprises (employing 51-250 people), (b3) large companies (employing more than 250 people) (c1) with domestic capital, (c2) with foreign capital.

In line with the above presented methodology, a list of companies has been prepared that meet the required in the definition of population criteria: management system in place, the type of business production or selected services. The last criterion of selection was related to the cost-aspect concerning further research. The population estimated 372 companies, and sample size of 100 companies was selected.

Due to the industry criterion, among respondents there were mostly companies of the metal industry (24\%), automotive (19\%) and machinery (9\%). Full crosssection of industries is shown in Figure 1.

The questionnaire included a total of 37 tools and techniques of quality management. One of the keys to their inclusion in the questionnaire were operating in theory (and practice) classification divisions into such groups of quality tools as: traditional, new, statistical and additional; and the group of quality techniques, where each of the listed groups of instruments covered comparable number of seven to eight representatives:

- traditional quality tools group: check sheet, histogram, control chart, fishbone diagram, Pareto diagram, flowchart, scatter diagram (TQT);
- new quality tools group: affinity diagram, relationship diagram, matrix diagram, tree diagram, prioritization matrix, process decision program chart, arrow diagram (NQT);

- statistical quality tools group: sampling (selection of samples for statistical surveys), statistics (statistical measures of location and variability), distributions (distributions of statistics described by the probability distribution function), interval of confidence (determination of the confidence interval of the average or fraction), hypothesis testing (formulation and verification of statistical hypotheses), analysis of variance, regression and correlation analysis, process capability indices (SQT);

- additional quality tools group: brainstorming, $\mathrm{ABCD}$ method, decision matrix, force field analysis, $\mathrm{ABC}$ method, 5W2H, 5S, Poka-Yoke/Mistake proofing (AQT);

- quality techniques group: QFD, FMEA, DoE, statistical quality inspection, SPC, MSA, testing requirements and satisfaction of customers (QT).

A standardized questionnaire was designed in a way that allowed - while indicating by the respondent wellknown and used in the audited company tool / technique of quality - simultaneous determination of:

- at which stage of the production process it is useful (in case of bigger number of adequate tools, respondents had to identify the most commonly used tool), wherein in the production process the following steps have been identified:

- market research (1-MR)

- designing of the product (2-DP)

- technical preparation of production (3-TPP)

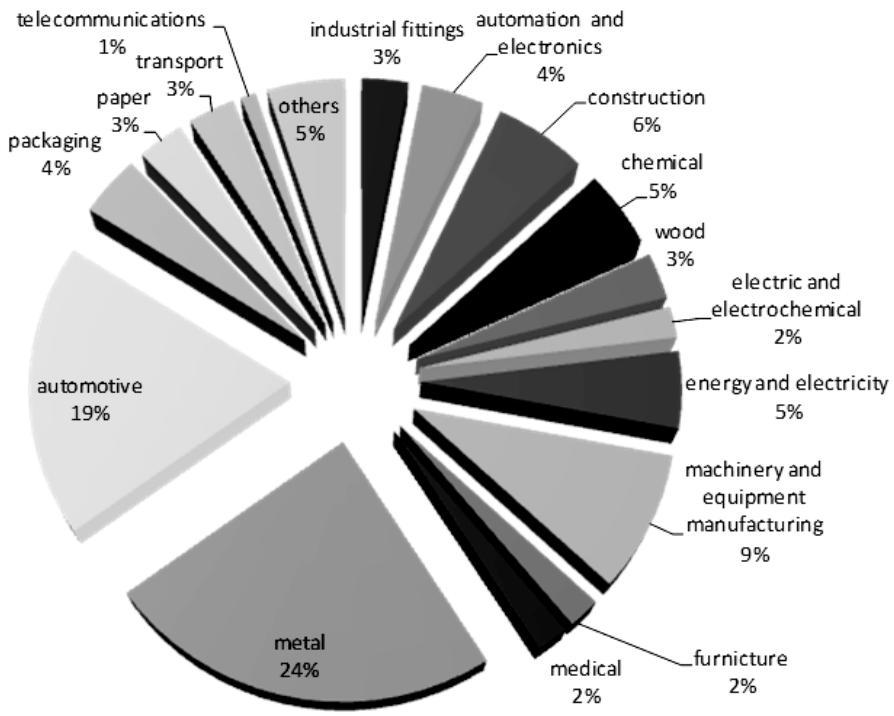

Figure 1: Companies surveyed (100 respondents) according to the industry 
- manufacturing process (4-MP)

- monitoring and measurement (5-MM)

- $\quad$ transport (6-T)

- $\quad$ warehousing $(7-\mathrm{W})$

- $\quad$ sales $(8-\mathrm{S})$

- $\quad$ support service (9-SS)

- $\quad$ utilization of the product (10-UP)

- what problem solving it is designed to solve (without reference to the phase of the methodology of problem solving):

- man

- low qualifications (1)

- poor work culture (2)

- interpersonal conflicts (3)

- lack of motivation and engagement (4)

- lack of creativity (5)

- others $(6)$

- material

- non-compliance (low quality) (7)

- inhomogeneity (once well, once wrong) (8)

- deliveries with inadequate quantity (9)

- delivery not on time (10)

- others (11)

- method

- inadequate manufacturing techniques, methods of service delivery, etc. (12)

- lack of full information about the process (13)

- others (14)

- machine

- too low quality ability of a machine, device, equipment (15)

- $\quad$ high failure rate (16)

- difficulties to use (17)

- others (18)

- performance of the process

- process instability/variability of the results of the process (19)
- high number of discrepancies / high fraction of defects (20)

- low efficiency (21)

- high costs of quality (22)

- others (23)

- monitoring and measurement

- insufficient process control (24)

- insufficient acceptance criteria of the performed work (25)

- measurement methods inadequate to the requirements (26)

- inappropriate measurement \& control instruments (27)

- others (28)

- management

- downtime (29)

- delays (30)

- creation of „bottlenecks” (31)

- lack of standards concerning work performance (32)

- „,bureaucracy” of the process (33)

- inadequate flow of information (34)

- too little data analysis and presentation of the results (35)

- lack of feedback information concerning noncompliance (36)

- too short time on decision making (37)

- ineffective supervision of documentation (38)

- others (39)

- environment

- difficult cooperation with suppliers (40)

- inadequate working conditions (41)

- others (42).

Subsequently, on the basis of the collected during the research data, qualitative reasoning has been conducted, which included an analysis of the occurring problems during specified stages in the production process and

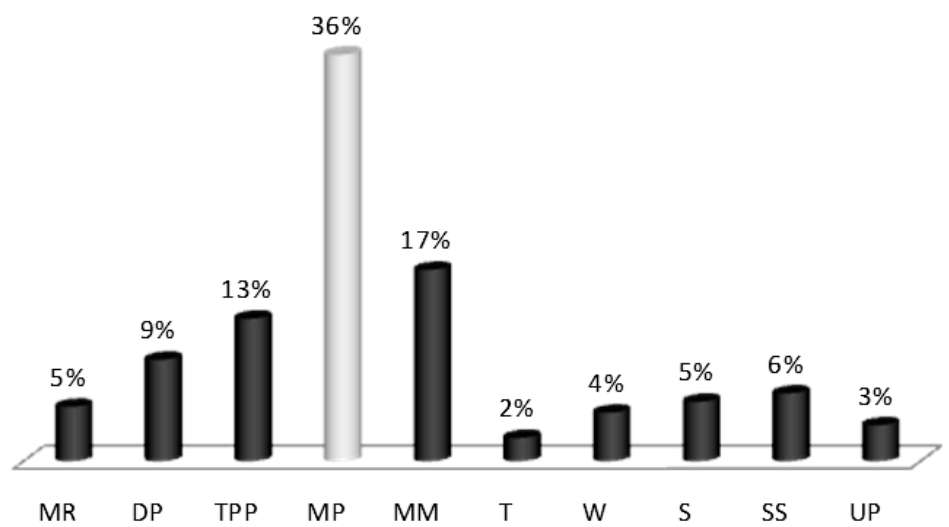

Figure 2: Number of indications (in \%) of problems that occur at different stages of the production process in the surveyed enterprises 
identification of quality management tools used in practice to solve them.

\section{Results}

Due to the data collected in the survey one may observe that the quality tools and techniques are used to solve problems of various kinds, most frequently however (Figure 2):

in the process of production ( $36 \%$ of all responses);

- in the direct "neighborhood" of the manufacturing process, i.e. in the technical preparation of production (13\% of responses), and in the control processes and measurements (altogether 17\% of responses);
- as well as in the "further environment" of the manufacturing process - in the design of products ( $9 \%$ of responses) and servicing ( $6 \%$ of responses).

QT\&T instruments are used less frequently in such phases of the production process as:

- market research and sales ( $5 \%$ of responses);

- warehousing and transport ( $4 \%$ and $2 \%$ of responses);

- in the utilization phase of products (3\% of responses).

Further part of the paper presents the results of analyses of data from the manufacturing phase (MP) in the production process. The rationale for the selection of the step "manufacturing process" for further analysis is that during the manufacturing process occur most problems ( $36 \%$ of the earlier mentioned indications); they are at the same time

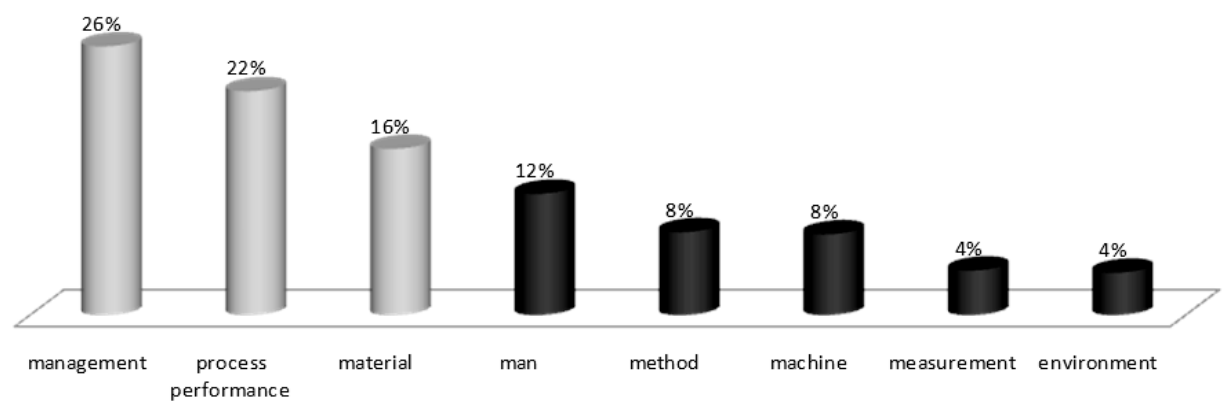

Figure 3: The frequency of indications to subcategories of problems in the manufacturing processes of the surveyed companies

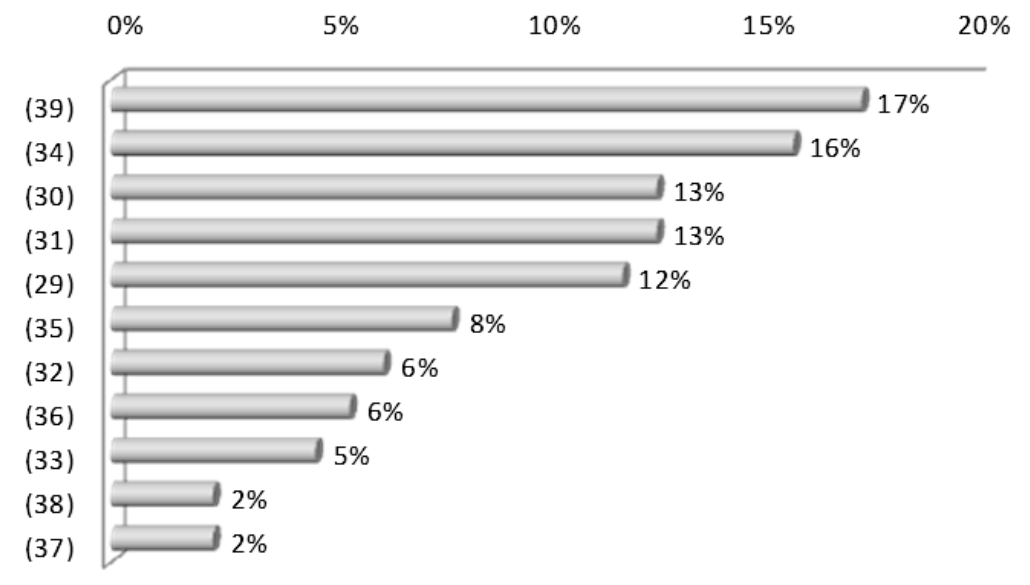

Legend:

(39) others

(34) inadequate flow of information

(30) delays

(31) formation of 'bottlenecks'

(29) downtime
(35) too little data analysis and presentation of results

(32) lack of standards concerning work performance

(36) lack of feedback information on discrepancies

(33) "bureaucracy" of the process

(38) ineffective monitoring of documentation

(37) too short time on decision making

Figure 4: The frequency of indications to subcategories of the problem "management" of manufacturing process 
the representatives of all eight categories of problems, defined in the study. On the basis of the most common problems in the manufacturing process, i.e.

- management of the process;

- performance of the process;

- process supplying (materials and resources)

Their sub-categories have been indicated; one has also shown which tools are reached out for in the Polish manufacturing companies in order to solve the problems and how the effectiveness of their usage is evaluated (Figure 3).

\section{The problem in the manufacturing process - management}

Figure 4 shows that the most common problems in the category "management" of the manufacturing process - apart from the classified by respondents as "others" (17\%), are problems associated with inadequate flow of information in the process ("do not arrive on time to the appropriate recipients"). Furthermore, the distinguished problems are: arising delays, "bottlenecks" and downtime.

The most commonly used tools in solving specific problems include: brainstorming (altogether $28 \%$ of indications) flowchart (total $15 \%$ of responses) and the PDPC ( $9 \%$ of responses), and the degree of their use - as concerns the remaining tools - is shown in Figure 5.

Respondents also evaluated the validity of the analyzed problem for the stability of the manufacturing process. Moreover, they estimated the importance of the occurring problem using a scale from 1 - little importance to 5 - very high importance. Among the respondents indicating occurrence of problems related to the management (on the significance of problems there were altogether 93 indications of 126 possible problems in this category)

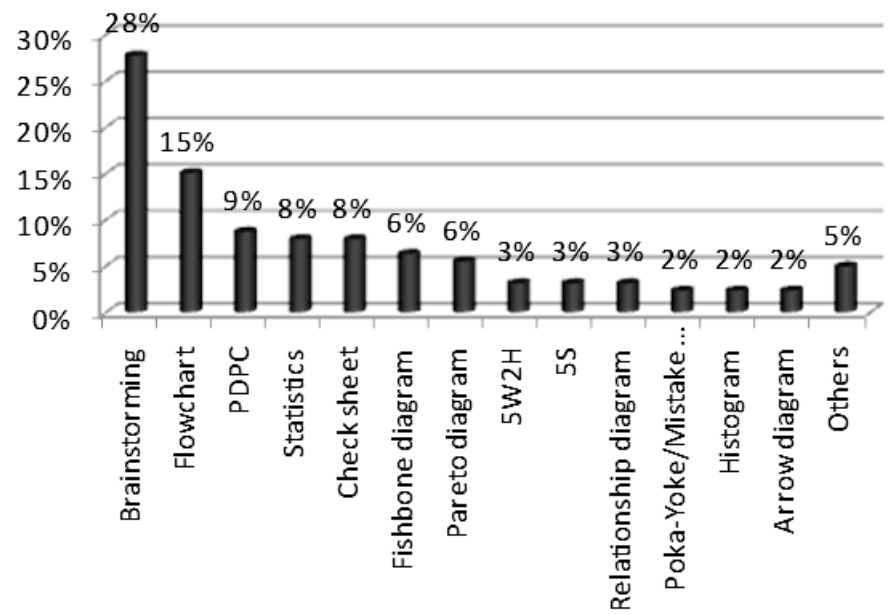

Figure 5: Tools and methods of quality management used in solving problems of the category "management"

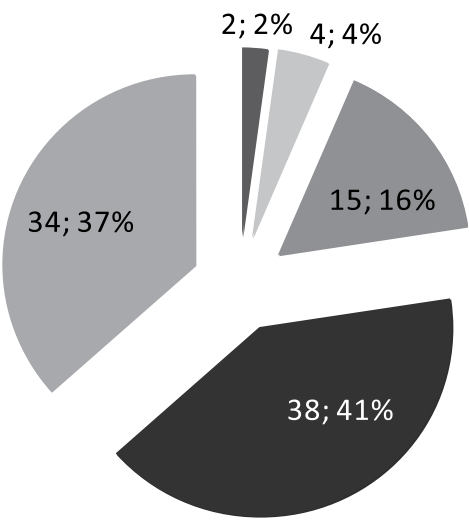

$1 \square 2 \square 3 \square 4 \square 5$

Figure 6: The significance of the problems associated with the management of the manufacturing process 
$78 \%$ of them identified these problems as important and very important (Figure 6).

Another aspect was to evaluate the effectiveness of the use of quality management tools, which are used to solve problems in the category of "management". There was a total of 125 indications to 126 possible. As many as $83 \%$ of respondents identified effectiveness of the evaluated tools as high and very high (Figure 7).

\section{The problem in the manufacturing process - the per- formance of the process}

Figure 8. shows that the most common problems in the category of "process performance" are a large number of dis- crepancies / defects fraction ( $30 \%$ of indications), variability of the process results ( $28 \%$ of responses) and low efficiency of the process (19\% of responses).

The most commonly used tools in dealing with specified problems include descriptive statistics $(20 \%$ of responses), Pareto diagram (12\% of responses) and process capability indicator ( $10 \%$ of responses), the degree of their usage - as concerns the remaining tools - is shown in Figure 9.

Respondents also evaluated the validity of the analyzed problem for the stability of the manufacturing process. Among the respondents indicating the occurrence of problems related to the performance of the process (on the significance of problems there were altogether

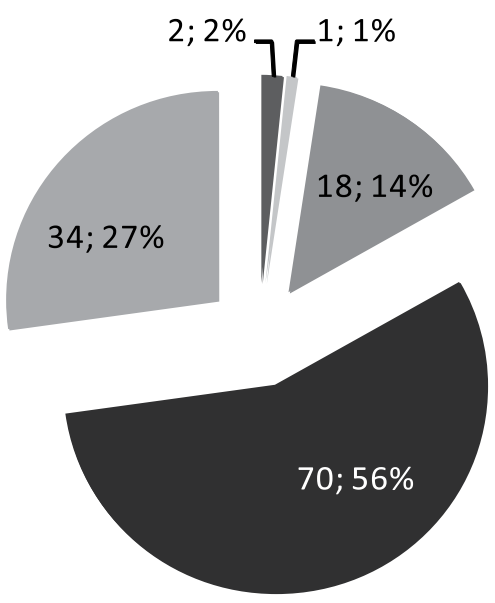

$1 \square 2 \square 3 \square 4 \square 5$

Figure 7: The effectiveness of the tools used to solve problems in the category "management"

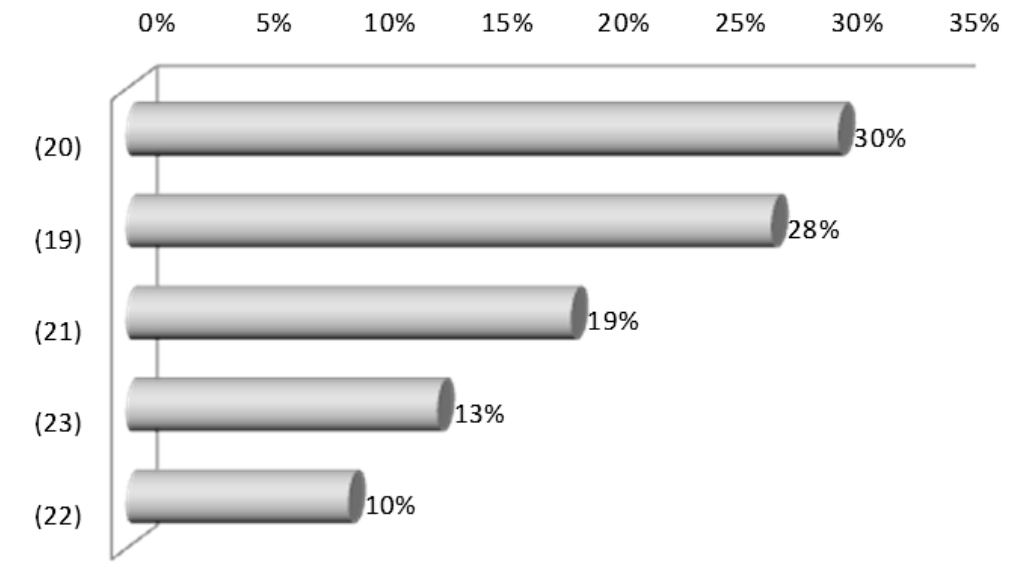

Legend:

(21) low efficiency

(20) a large number of discrepancies / high fraction of defects

(23) others

(19) process instability / variability of process results

(22) high costs concerning quality

Figure 8: The frequency of indications to subcategories of the problem "process performance" 


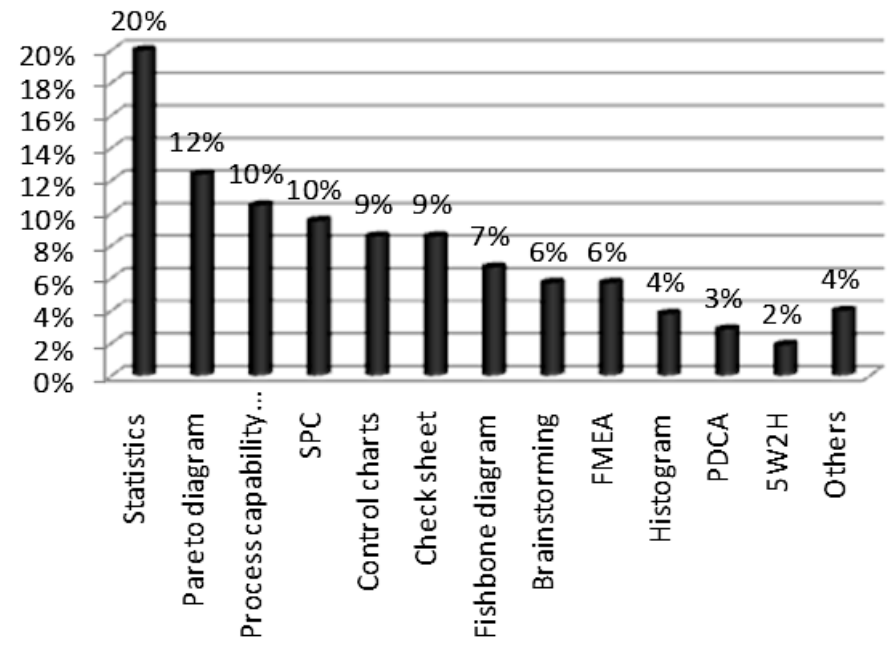

Figure 9: Tools and methods of quality management used in problem solving in the category of "process performance"

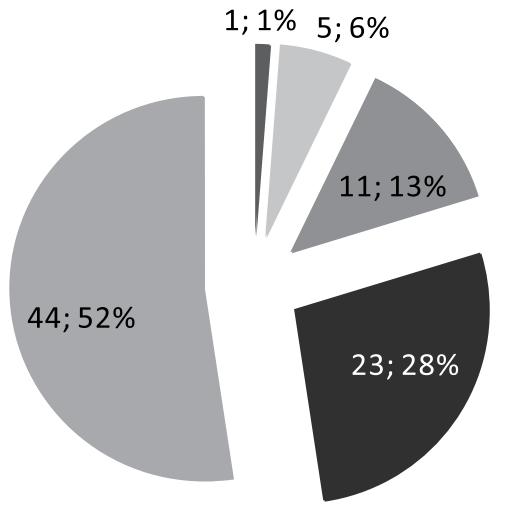

$1 \square 2 \square 3 \square 4 \square 5$

Figure 10: The significance of the problems associated with the performance of the manufacturing processes

84 indications to 105 possible problems in this category) $80 \%$ of respondents identified these problems as important and very important (Figure 10).

Another aspect was to evaluate the effectiveness of the usage of quality management tools, which are applied to solve problems in the category of "process performance". A total of 103 indications has been obtained per 105 possible. As many as $86 \%$ of respondents identified effectiveness of the evaluated tools as high and very high (Figure 11).

\section{The problem in the manufacturing process - material (of process supply)}

Figure 12 shows that the most common problems in the category of "process supply" are low quality of input material (37\% of responses), followed by deliveries against the quantitative specification (21\% of responses) and the inhomogeneity of the supplied materials (18\% of responses).

The most commonly used tools in dealing with specified problems include: the check sheet $(26 \%$ of responses), statistical control of deliveries ( $17 \%$ of responses) and also FMEA method (13\% of responses), the degree of their use - as concerns the remaining tools - is shown in Figure 13.

Respondents also evaluated the validity of the analyzed problem for the stability of the manufacturing process. Among the respondents indicating occurrence of problems related to the process supply (on the significance of problems there were altogether 68 indications of 78 possible problems in this category) $85 \%$ of 


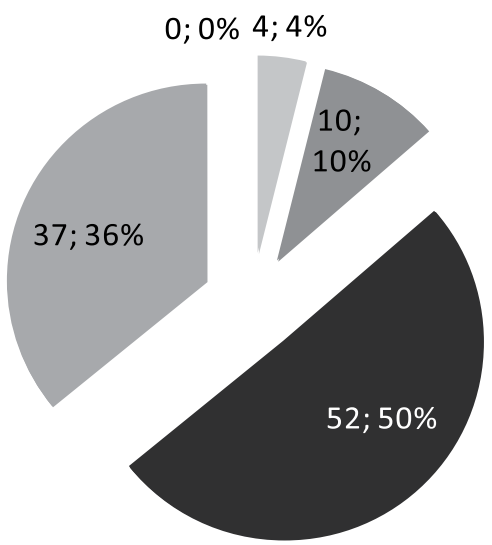

$1 \square 2 \square 3 \square 4 \square 5$

Figure 11: The effectiveness of the tools used to solve problems in category of "process performance"

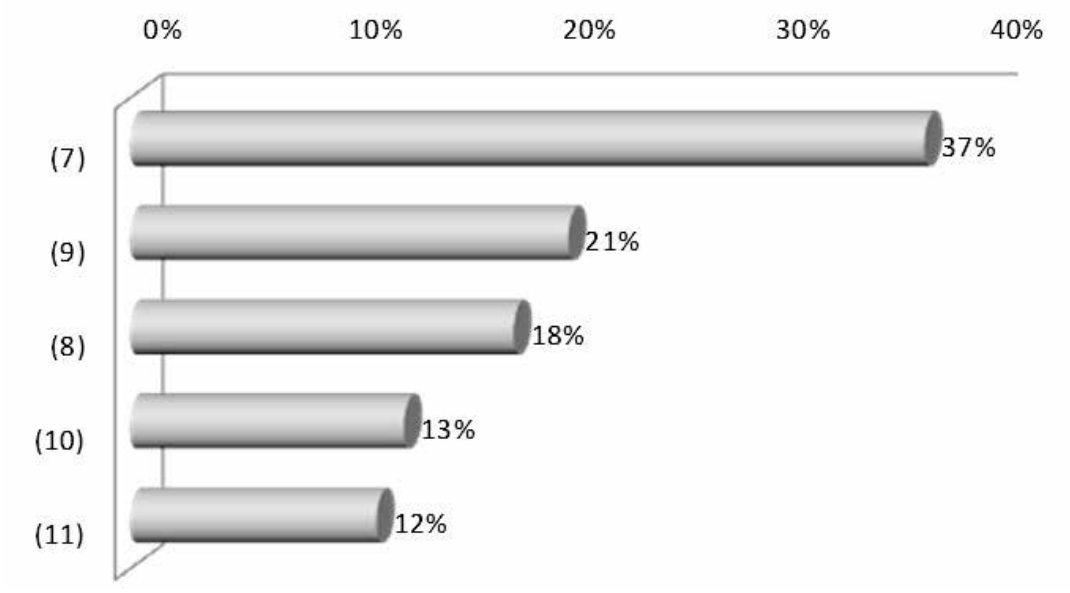

Legend:

(8) inhomogeneity (once well, once wrong)

(7) non-compliance (low quality)

(10) deliveries not on time

(9) deliveries with inadequate quantity

(11) others

Figure 12: The frequency of indications to subcategories of the problem "process supply"

respondents identified these problems as important and very important (Figure 14).

Another aspect was to evaluate the effectiveness of the usage of quality management tools, which are applied to solve problems in the category of "process supply." There was a total of 77 indications out of 78 possible. As many as $82 \%$ of respondents identified effectiveness of the evaluated tools as high and very high (Figure 15).

\section{Discussion and conclusions}

Application of tools and techniques of quality management is different at different stages of the production process
(Figure 16). The market research (MR) goes primarily to the collection of quality management techniques (QT) with the leading role of methods testing the requirements and satisfaction of customers. At this stage, statistical tools (SQT), new (NQT) and additional (AQT) are used sparsely. During the design, the complement of tools and engineering design systems are quality management techniques, together with traditional tools (TQT) and additional ones. The dominant set of quality tools at the stage of technical preparation of production (TPP) consists of QT, TQT and additional tools, while the first and second group of tools definitely stands out due to the highest number of indications of the respondents. 


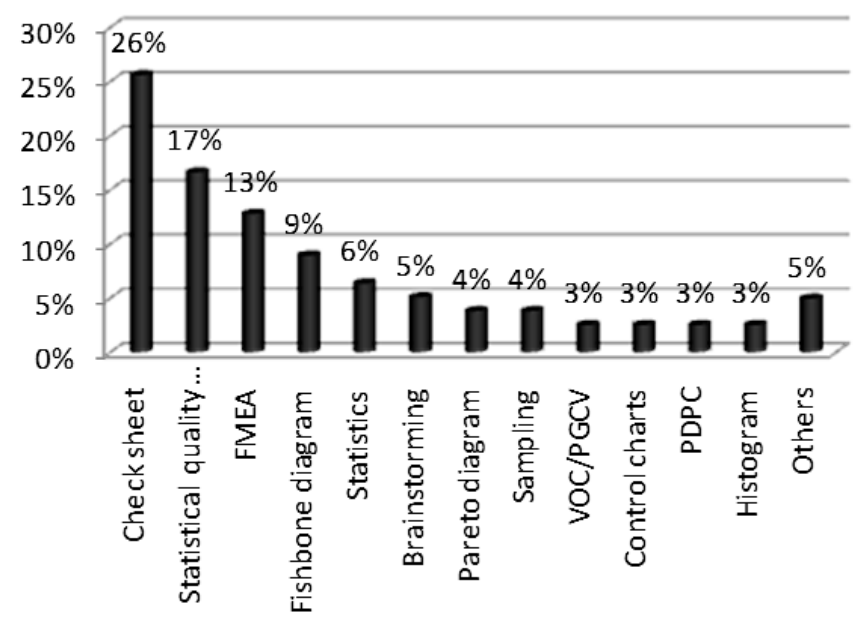

Figure 13: Tools and methods of quality management used in problem solving in the category of "process supply"

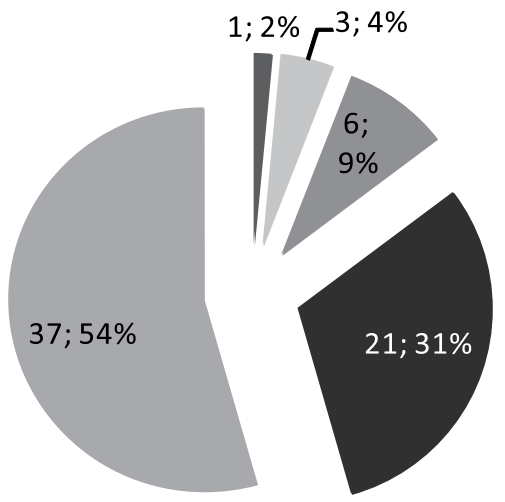

$\square 1 \square 2 \square 3 \square 4 \square 5$

Figure 14: The significance of the problems associated with the process supply

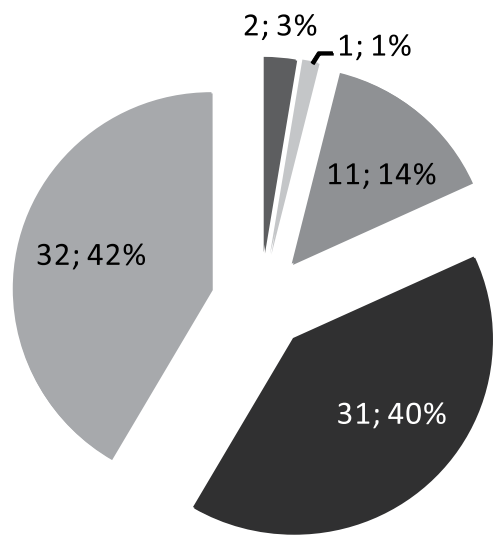

$1 \square 2 \square 3 \square 4 \square 5$

Figure 15: The effectiveness of the tools used in problem solving in the category of "process supply" 


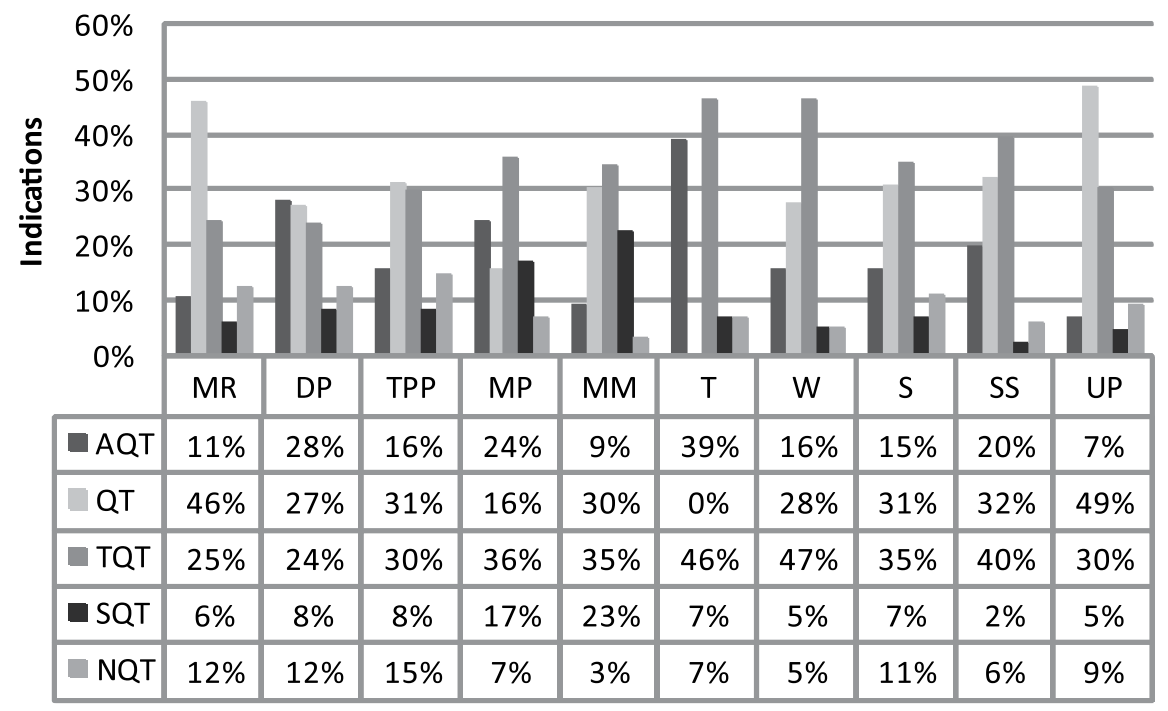

Figure 16: The frequency distribution of $Q T \& T$ indications in groups according to the stages in the production process

In the manufacturing process itself the most frequently used tools are those from the traditional group; in the second place - additional tools, which shall be a reference to the methods of organizing processes in a wider range. It is the area where new tools are most frequently used! (as compared with other stages of the production process). The latter ones, in turn, are least useful in the control phase and during the measurement (MM). In this part of the process one usually reaches for more complex instruments, that is the quality techniques (including SPC, MSA, DoE, statistical inspection), statistical tools and traditional tools (having in their sets also quantitative tools). During transport one uses tools and techniques of quality management least frequently (total 28 responses). They are more useful in the case of warehousing processes - in the context of controls and deployment of resources (traditional tools applied most frequently here). The system of indications to usage of QT \& T in the phase of service is derived from the techniques and tools used in the design and manufacturing phases (most indications concern TQT, QT and AQT), though their cardinality in these phases of the manufacturing process is much lower. It turns out that the quality tools and techniques are also useful in the EoL-phase of a product. This is particularly visible in the case of indications to the set of quality techniques and traditional tools, used in the phase of product utilization. Popularity of usage of quality tools and techniques in the UP phase - puts these instruments - due to the cardinality of indications throughout the whole production process - in the penultimate position in the ranking. One should however remember that problems related to the so-called end of the product's life have only recently been gaining in importance as far as the activity of manufacturing companies is concerned.
The collected data show that the tools and techniques of quality can be attributed to one of three categories:

- process-dedicated, are applied in selected stages of the manufacturing process (e.g., 4 - stage of manufacturing), and are also useful for solving all kinds of problems at this stage of the process, they can include: control sheets, descriptive statistics, block diagram and FMEA method;

- problem-dedicated; are used to solve problems of specified nature and are also useful at all stages of the manufacturing process, they may include: control sheets and block diagrams;

- so called "island-like", i.e. centered around the "neighboring" manufacturing process stages in connection with the problems of a specified nature, they may include: FMEA, SPC, DoE, indicators of qualitative abilities, sampling.

Gathered in the study material is a reflection of the degree of usage and suitability assessment - in the context of solving problems and improving processes - of quality tools and techniques in manufacturing companies in Poland. It is also a basis for the already developed decision support system of the selection of the tools and techniques of quality (Starzyńska, Hamrol, 2013). Surveys were carried out within the scope of one's own project, entitled "Development of a new - based on the knowledge of workers - method of selection and application of the quality management instruments for the improvement of manufacturing processes in manufacturing companies" (No. N503263234), funded by the Polish Ministry of Science and Higher Education, realized between 2008 and 2010 . 


\section{References}

Ahmed S., \& Hassan M. (2003). Survey and case investigations on application of quality management tools and techniques in SMIs. International Journal of Quality \& Reliability Management, 20(7), 795-826, http://dx.doi. org/10.1108/02656710310491221

Asaka T., \& Ozeki K. (1996). Handbook of quality tools. The Japanese approach, Portland, Oregon: Productivity Press, ISBN: 0915299453; 9780915299454

Bamford D.R., \& Greatbanks R.W. (2005). The use of quality management tools and techniques: a study of application in everyday situations. International Journal of Quality \& Reliability Management, 22(4), 376-392, http://dx.doi. org/10.1108/02656710510591219

Brassard M., \& Ritter D. (1994). The Memory Jogger - A Pocket Guide of Tools for Continuous Improvement \& Effective Planning. Methuen Massachusetts: GOAL/QPC, USA. ISBN: 1879364441; 9781879364448

Bunney H., \& Dale B. (1997). The implementation of quality management tools and techniques: a study. The TQM Magazine, 9(3), 183-189, http://dx.doi.org/10.1108/09544789710168966

Dahlgaard J.J., Chen C.K., Jang J.Y., Banegas L.A., \& DahlgaardPark S.M. (2013). Business excellence models: limitations, reflections and further development. Total Quality Management \& Business Excellence, 24(5), 519-538, http:// dx.doi.org/10.1080/14783363.2012.756745

Dale B.G., \& McQuater R.E. (1998). Managing Business Improvement and Quality: Implementing Key Tools and Techniques. Oxford: Blackwell Publishers, ISBN: 0631207872,9780631207870

Dean J.W., \& Bowen D.E. (1994). Management theory and Total quality: improving research and practice through theory development. Academy of Management Review, 19(3), 392418, http://dx.doi.org/10.5465/AMR.1994.9412271803

Gregory M. J. (1993). Integrated performance measurement: a review of current practice and emerging trends. International Journal of Production Economics, 30-31(1), 281-296, http:// dx.doi.org/10.1016/0925-5273(93)90099-7

Fukui R. et al. (2003). Handbook for TQM and QCC, Volume I and Volume II. Inter-American Development Bank (ID). Retrieved (July 9, 2014) from http://a3thinking.com/blog/wp-content/ uploads/2009/04/tqchandbookv1.pdf, http://a3thinking.com/ blog/wp-content/uploads/2009/04/tqchandbookv2.pdf
Herbert D., Curry A., \& Angel L. (2003). Use of quality tools and techniques in services. The Service Industries Journal, 23(4), 61-80, http://dx.doi.org/10.1080/02642060412331301012

Lagrosen Y., \& Lagrosen S. (2005). The effects of quality management-a survey of Swedish quality professionals. International Journal of Operations \& Production Management, 25(10), 940-952, http://dx.doi.org/10.1108/01443570510619464

McQuater R.E., Dale B.G., Boaden R.J., \& Wilcox M. (1996). The effectiveness of quality management tools and techniques: an examination of the key influences in five plants, In: Proceedings of the Institution of Mechanical Engineers, Part. B: Journal of Engineering Manufacture, 210(B4), 329-339.

McQuater R.E., Scurr C.H., Dale B.G., \& Hillman P.G. (1995). Using quality tools abs techniques successfully. The TQM Magazine, 7(6), 37-42.

Rooney J.J., \& Heuvel L.N.V. (2004). Root Cause Analysis For Beginners. Quality Progress, 37(7), 45-53.

Shiba S., \& Walden D. (2002). Quality process improvement tools and techniques, Technical Report, MIT, USA. Retrieved June 9, 2014 from http://www.walden-family.com/public/ iaq-paper.pdf

Starzyńska B., \& Hamrol A. (2013). Excellence toolbox: Decision support system for quality tools and techniques selection and application. Total Quality Management \& Business Excellence, 24(5), 577-595, http://dx.doi.org/10.1080/14783 363.2012 .669557

Tague N.R. (2005). The Quality Toolbox. Milwaukee: ASQ Quality Press.

Tang L.C., Goh T.N., Lam S.W., \& Zhang C.W. (2007). Fortification of Six Sigma: Expanding the DMAIC Toolset. Quality and Reliability Engineering International, 23(1), 3-18, http:// dx.doi.org/10.1002/qre.822

Tarí J.J., Molina J.F., \& Castejón J.L. (2007). The relationship between quality management practices and their effects on quality outcomes, European Journal of Operational Research, 183(2), 483-501, http://dx.doi.org/10.1016/j.ejor.2006.10.016

Beata Starzyńska is an Assistant Professor in the Department of Management and Production Engineering, Faculty of Mechanical Engineering and Management, Poznan University of Technology, Poznań, Poland. Her research activities cover quality engineering, integrated management systems and knowledge management, as well as quality tools \& techniques application in manufacturing companies. 